Elsevier Editorial System(tm) for Colloids and Surfaces A: Physicochemical and Engineering Aspects Manuscript Draft

Manuscript Number:

Title: Effects of micelle nature and concentration on the acid dissociation constants of the metal extractor PADA

Article Type: Research Paper

Keywords: SDS; DTAC; Triton X-100; surface potential; surfactant

Corresponding Author: Prof. Fernando Secco, Ph.D.

Corresponding Author's Institution: University of Pisa

First Author: Sabriye Aydinoglu, Department of Analytical Chemistry

Order of Authors: Sabriye Aydinoglu, Department of Analytical Chemistry; Tarita Biver, Ph. D.; Fernando Secco; Marcella Venturini

Abstract: The pyridine-2-azo-p-dimethylaniline (PADA) ligand presents two acid dissociation constants, being $\mathrm{pKa} 1$ related to the pyridinium and $\mathrm{pKa} 2$ related to the anilinium residue. These have been measured by spectrophotometric titrations in aqueous solutions containing either the anionic (SDS), or the non-ionic (Triton X-100) or the cationic (DTAC) surfactants. The pKai shifts of the charged systems from that of the PADA/Triton X-100 reference $(\Delta$ pKai0) are compared. For PADA/DTAC $\Delta$ pKa $10=0.05$ and $\Delta$ pKa20 $=0.6$. For PADA/SDS $\Delta$ pKa10 $=2.1$ and $\Delta$ pKa20 $=2.1$ both yielding the value of $-126 \mathrm{mV}$ for the surface potential $(\psi)$ of SDS. The $\psi$ value, lying between the calculated Stern potential and the zeta potential, indicates that the dye is located on the SDS micelles between the fixed and the shear layer. In contrast, the behaviour of PADA/DTAC is explained assuming that the positively charged deprotonation sites of PADA are forced to protrude towards the bulk solvent by the positive charges of DTAC micelles. The shifts of the apparent pKai from the aqueous values ( $\Delta$ pKaiw) have also been analysed. Concerning PADA/Triton X-100, the shifts $\Delta \mathrm{pKa} 1 \mathrm{w}=-0.1$ and $\triangle \mathrm{pKa} 2 \mathrm{w}=-0.9$ are rationalized in terms of dielectric constant reduction at the reaction sites. Concerning PADA/DTAC, $\Delta \mathrm{pKa} 1 \mathrm{w}=-0.05$ and $\Delta \mathrm{pKa} 2 \mathrm{w}=-0.3$ whereas, for PADA/SDS, $\Delta \mathrm{pKa} 1 \mathrm{w}=2.0$ and $\triangle \mathrm{pKa} 2 \mathrm{w}=1.2$. The $\mathrm{pKa} 2 \mathrm{w}$ values decrease on raising the surfactant concentrations for all the investigated systems. This behaviour is explained assuming that the increase of the overall micellar surface and, by consequence, of the reaction sites number, results in a site dilution effect which disfavours proton association. The addition of $\mathrm{NaCl}$ induces changes of $\mathrm{pKa} 1$ and $\mathrm{pKa} 2$ which are explained in terms of (large) reduction of $\psi$ for PADA/SDS and of (small) reduction of the dielectric constant for the other systems.

Suggested Reviewers: Julian Eastoe

School of Chemistry, University of Bristol (UK)

julian.eastoe@bristol.ac.uk

Expert on colloids and micelles

Brian Hugh Robinson

School of Chemical Sciences \& Pharmacy, University of East Anglia, Norwich, England thematurbo@aol.com 
Expert on micelles

Tiziana Pivetta

Department of Chemical Sciences, University of Cagliari (Italy)

tpivetta@unica.it

Expert on protonation constants evaluation and solution equilibria in complex systems

Elia Grueso

Departamento de Quimica Fisica, University of Sevilla (Spain)

elia@us.es

Expert on potentials and physico-chemical espects of solution equilibria

Christian Tondre

Laboratoire de Chimie Physique Organique et Colloïdale, Université Henri Poincaré-Nancy -France tondre@lesoc.uhp-nancy.fr

Expert on colloids 
Dear Editor,

we submit to your attention the article entitled:

\section{Effects of micelle nature and concentration on the acid dissociation constants of the metal extractor PADA}

by Sabriye Aydinoglu, Tarita Biver, Fernando Secco and Marcella Venturini

to be considered for publication in Colloids and Surfaces A.

This paper reports on a detailed analysis of the influence of anionic (SDS), non-ionic (Triton X100) or cationic (DTAC) micellar media on the acid-base characteristics of a metal extracting ligand (pyridine-2-azo-p-dimethylaniline, PADA). The in depth analysis here presented for PADA could represent a guideline to be employed to predict the behaviour of similar systems, and therefore, of interest for a wide readership.

The interest on the effects of surfactants on drug properties is continuously increasing and micellar systems have attracted attention also as potential extracting media, in particular for precious/toxic metal ions. The $\mathrm{H}^{+}$concentration in the bulk solution generally differs from the value on the micelle surface and this can have dramatic repercussions on the acid characteristic of a weak acid (as many ligands are) and, therefore, on the speciation of the ligand on the micelle surface.

Despite the increasing interest on surfactants and micellar phases and the work of different authors, some details of the reactivity changes of ligands on the micellar phase still need to be analysed and/or are often underestimated.

The results of this work clearly indicate that for the analysed ligand both the $\mathrm{pK}_{\mathrm{a} 1}$ and $\mathrm{pK}_{\mathrm{a} 2}$ shifts induced by the presence of micelles strongly depend on the protolytic equilibrium involved, on the charge of the micelles, on the dye components absorbed and on the ionic medium (absence or presence of $\mathrm{NaCl}$ ). These shifts are discussed on the basis of surface potential ( $\psi$ ) of SDS, ligand position on the micelle, dielectric constant reduction at the reaction sites and site dilution effects.

With kindest regards

Fernando Secco

Tarita Biver 
The pKs of PADA ligand shift in the presence of micelles, depending on equilibrium involved, charge of the micelles, dye components absorbed and ionic medium

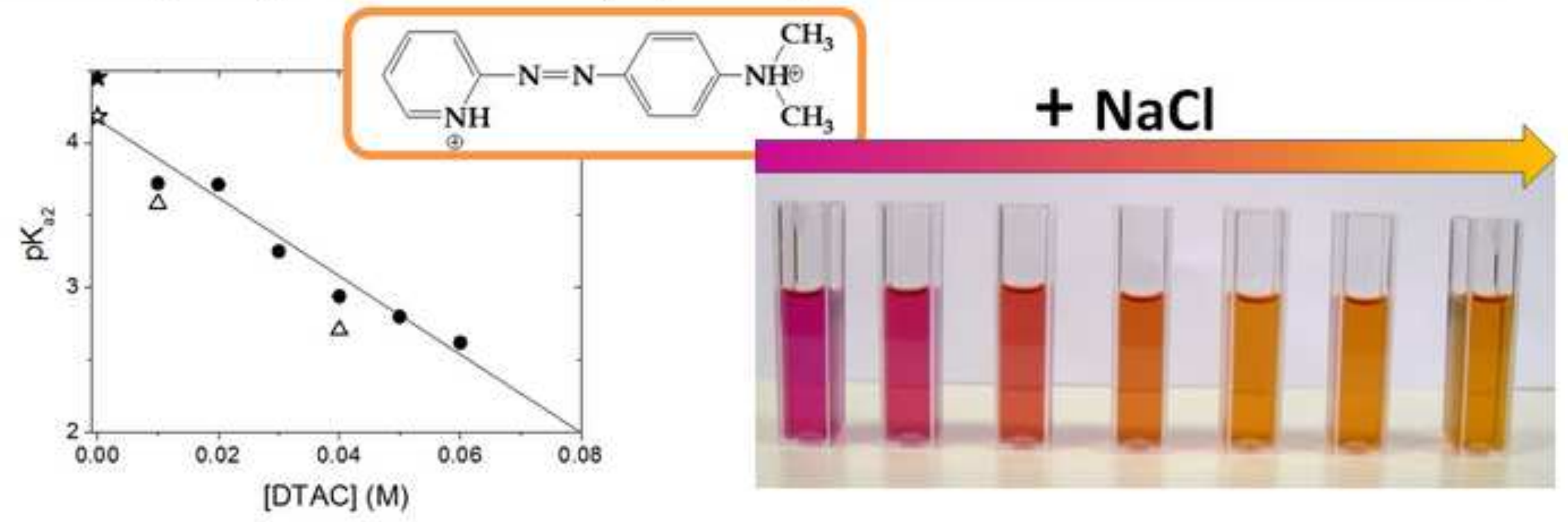




\section{Highlights}

- SDS (-), DTAC (+) or TritonX (non-ionic) micelles differently affect PADA's pKs

- In the SDS negative micelle, PADA is located between the fixed and the shear layer

- In the DTAC positive micelle, PADA protrudes towards the bulk solvent

- In Triton X, dielectric constant reduction at the reaction sites occurs

- $\mathrm{NaCl}$ induces reduction of surf. potential (SDS) or of dielectric constant (others) 


\title{
Effects of micelle nature and concentration on the acid dissociation constants of the metal extractor PADA
}

\author{
Sabriye Aydinoglu ${ }^{a}$, Tarita Biver $^{b} *$ Fernando Secco $^{b} *$ Marcella Venturini $^{b}$ \\ ${ }^{a}$ Department of Analytical Chemistry, Faculty of Pharmacy, Cukurova University, 01330 Adana, Turkey \\ ${ }^{\mathrm{b}}$ Dipartimento di Chimica e Chimica Industriale - Università di Pisa - Via Risorgimento 35 - 56122 - Pisa (Italy) \\ E- mails: sabriyeaydinoglu@gmail.com (S. Aydinoglu); tarita.biver@unipi.it (T. Biver); fernando.secco@unipi.it (F. \\ Secco); marcella.venturini@dcci.unipi.it (M. Venturini)
}

Correspondig Authors: T. Biver and F. Secco Department of Chemistry and Industrial Chemistry, University of Pisa, Via Risorgimento 35, 56126 Pisa (Italy); tarita.biver@unipi.it, fernando.secco@unipi.it, Phone: +390502219259, Fax: +390502219260

\begin{abstract}
The pyridine-2-azo-p-dimethylaniline (PADA) ligand presents two acid dissociation constants, being $\mathrm{pK}_{\mathrm{a} 1}$ related to the pyridinium and $\mathrm{pK}_{\mathrm{a} 2}$ related to the anilinium residue. These have been measured by spectrophotometric titrations in aqueous solutions containing either the anionic (SDS), or the non-ionic (Triton X-100) or the cationic (DTAC) surfactants. The $\mathrm{pK}_{\mathrm{ai}}$ shifts of the charged systems from that of the PADA/Triton $\mathrm{X}-100$ reference $\left(\Delta \mathrm{pK}_{\mathrm{ai}}{ }^{0}\right)$ are compared. For PADA/DTAC $\Delta \mathrm{pK}_{\mathrm{a} 1}{ }^{0}=0.05$ and $\Delta \mathrm{pK}_{\mathrm{a} 2}{ }^{0}=0.6$. For PADA/SDS $\Delta \mathrm{pK}_{\mathrm{a} 1}{ }^{0}=2.1$ and $\Delta \mathrm{pK}_{\mathrm{a} 2}{ }^{0}=2.1$ both yielding the value of $-126 \mathrm{mV}$ for the surface potential $(\psi)$ of SDS. The $\psi$ value, lying between the calculated Stern potential and the zeta potential, indicates that the dye is located on the SDS micelles between the fixed and the shear layer. In contrast, the behaviour of PADA/DTAC is explained assuming that the positively charged deprotonation sites of PADA are forced to protrude towards the bulk solvent by the positive charges of DTAC micelles. The shifts of the apparent $\mathrm{pK}_{\mathrm{ai}}$ from the aqueous values $\left(\Delta \mathrm{pK}_{\mathrm{ai}}{ }^{\mathrm{w}}\right)$ have also been analysed. Concerning PADA/Triton $\mathrm{X}-100$, the shifts $\Delta \mathrm{pK}_{\mathrm{a} 1}{ }^{\mathrm{w}}=-0.1$ and $\Delta \mathrm{pK}_{\mathrm{a} 2}{ }^{\mathrm{w}}=-0.9$ are rationalized in terms of dielectric constant reduction at the reaction sites. Concerning PADA/DTAC, $\Delta \mathrm{pK}_{\mathrm{a} 1}{ }^{\mathrm{w}}=-0.05$ and $\Delta \mathrm{pK}_{\mathrm{a} 2}{ }^{\mathrm{w}}=-0.3$ whereas, for PADA/SDS, $\Delta \mathrm{pK}_{\mathrm{a} 1}{ }^{\mathrm{w}}=$
\end{abstract}


2.0 and $\Delta \mathrm{pK}_{\mathrm{a} 2}{ }^{\mathrm{w}}=1.2$. The $\mathrm{pK}_{\mathrm{a} 2}{ }^{\mathrm{w}}$ values decrease on raising the surfactant concentrations for all the investigated systems. This behaviour is explained assuming that the increase of the overall micellar surface and, by consequence, of the reaction sites number, results in a site dilution effect which disfavours proton association. The addition of $\mathrm{NaCl}$ induces changes of $\mathrm{pK}_{\mathrm{a} 1}$ and $\mathrm{pK}_{\mathrm{a} 2}$ which are explained in terms of (large) reduction of $\psi$ for PADA/SDS and of (small) reduction of the dielectric constant for the other systems.

Keywords: SDS, DTAC, Triton X-100, surface potential, surfactant

\section{Abbreviations}

PADA Pyridine-2-azo-p-dimethylaniline

SDS Sodium dodecyl sulphate

DTAC Dodecyl trimethyl ammonium chloride

Triton X-100 Polyethylene glycol p-(1,1,3,3-tetramethylbutyl)-phenyl ether

$\Delta \mathrm{pK}_{\mathrm{ai}}{ }^{0} \quad \mathrm{pK}_{\mathrm{ai}}$ shift of the charged systems from that of the PADA/Triton X-100 reference system

$\Delta \mathrm{pK}_{\mathrm{ai}}{ }^{\mathrm{w}} \quad$ apparent $\mathrm{pK}_{\mathrm{ai}}$ shift from the value in water 


\section{Introduction}

The molecular structure of surfactants and their unusual properties leads to both widespread and highly specialized applications [1-5]. Surfactant micellar media can increase the solubility of the substances poorly soluble in water. This is of a special significance in the field of drug action, since aqueous micellar systems can simulate far more complex biological systems. Because of that, the interest on the effects of surfactants on drug properties is continuously increasing [6]. Moreover, micellar systems have attracted attention also as potential extracting media, in particular for precious/toxic metal ions [7]. The replacement of the organic phase by pseudo-phases built up with surfactants offers an attractive alternative to classical, environmental unfriendly water/organic solvent extraction. Extracting agents (or ligands), have often limited solubility in water, but this is considerably enhanced in micellar solutions. Moreover, the hydrogen ion concentration in the bulk solution generally differs from the value on the micelle surface. For instance, in the presence of SDS micelles, the negatively charged surface will attract protons, resulting in an increase of proton concentration at the micelle surface with a consequent decrease of $\mathrm{pH}$. This effect can have dramatic repercussions on the acid characteristic of a weak acid (as many ligands are) and, therefore, on the speciation of the ligand on the micelle surface. Based on the Boltzmann's law of charged particle distribution in the presence of an electrically charged surface, Hartley and Roe [8] assumed that the proton activity $\left(\mathrm{a}_{\mathrm{H}}^{+} \mathrm{s}\right)$ on a surface at the potential $\psi$ (that they identify as the $\zeta$ potential) differs from that in the bulk water $\left(\mathrm{a}_{\mathrm{H}}{ }^{+} \mathrm{w}\right)$ according to the relationship $\left(\mathrm{a}_{\mathrm{H}}{ }^{+}\right) /\left(\mathrm{a}_{\mathrm{H}}{ }^{+} \mathrm{w}\right)=$ $\exp (-F \psi / R T)$ which, at $25^{\circ} \mathrm{C}$, can be rewritten as equation (1)

$\mathrm{pH}_{\mathrm{s}}-\mathrm{pH}_{\mathrm{w}}=\psi / 59.2$

where $\psi$ is expressed in $\mathrm{mV}$ and has the same sign as that of the micelle charge. Hence, addition of an anionic surfactant (as SDS) to an aqueous solution results in a decrease of $\mathrm{pH}$ at the interface 
whereas addition of a cationic surfactant (as DTAC) makes the $\mathrm{pH}$ on the micelle surface higher with respect to the bulk solution $\mathrm{pH}$.

The $\mathrm{pK}_{\mathrm{a}}$ of a weak acid, located on the micelle surface, is also shifted and the above authors attributed the $\mathrm{pK}_{\mathrm{a}}$ shift to the change of proton concentration close to the micelle surface, disregarding any possible intrinsic effect arising from changes in the environment [9]. According to this assumption, the surface $\mathrm{pK}_{\mathrm{a}}\left(\mathrm{pK}_{\mathrm{a}}^{\mathrm{s}}\right)$, is related to the bulk $\mathrm{pK}_{\mathrm{a}}\left(\mathrm{pK}_{\mathrm{a}}{ }^{\mathrm{w}}\right)$, by equation (2) valid at $25^{\circ} \mathrm{C}[8,10]$.

$\mathrm{pK}_{\mathrm{a}}^{\mathrm{s}}-\mathrm{pK}_{\mathrm{a}}{ }^{\mathrm{w}}=-\psi / 59.2$

However, the equilibrium of a weak acid bound to a surface may be affected not only by the electrostatic potential but, in addition, by the local characteristics of the environment. In effect it was observed that the $\mathrm{pK}_{\mathrm{a}}$ values of umbrelliferone, bromthymol bue and methyl red were shifted by neutral micelles [11]. Such an observation makes equation (2) unsuitable to evaluate the surface potential of a micelle or, alternatively, to evaluate $\left(\mathrm{pK}_{\mathrm{a}}^{\mathrm{s}}\right)$ from the known values of $\left(\mathrm{pK}_{\mathrm{a}}{ }^{\mathrm{w}}\right)$ and $\psi$. In order to derive the value of the electrostatic contribution to the free energy of a protolytic equilibrium in the presence of charged micelles, the reference system, devised as $\left(\mathrm{pK}_{\mathrm{a}}{ }^{\mathrm{w}}\right)$ by Hartley and Roe, should be replaced by the "intrinsic" parameter $\left(\mathrm{pK}_{\mathrm{a}}^{\mathrm{i}}\right)$ corresponding to the surface $\mathrm{pK}_{\mathrm{A}}$ of the probe in the absence of surface potential [12]. Under the hypothesis that the contribution of the local environment remains the same, independently of the surface charge, $\left(\mathrm{pK}_{\mathrm{a}}{ }^{\mathrm{i}}\right)$ can be replaced by $\left(\mathrm{pK}_{\mathrm{a}}{ }^{0}\right)$, the probe $\mathrm{pK}_{\mathrm{a}}$ measured in the presence of uncharged micelles [13] (equation (3)).

$\mathrm{pK}_{\mathrm{a}}^{\mathrm{s}}-\mathrm{pK}_{\mathrm{a}}{ }^{0}=-\psi / 2.3 \mathrm{RT}$

Pyridine-2-azo-p-dimethylaniline (PADA) is a diprotic acid that dissociates as shown in Figure 1 [14]. It is widely used as a metal extractor in micellar enhanced extraction processes $[15,16]$ owing 
to the property of being almost totally adsorbed in many micelles including SDS, DTAC and Triton $\mathrm{X}-100$, the surfactants employed in the present work.

In the framework of our studies on metal extraction using MEUF [17-20] we have investigated the influence exerted by micelles of different concentration and charges on the acidity constants of PADA. The results of this work and the comparison with literature results clearly indicate that both the $\mathrm{pK}_{\mathrm{a} 1}$ and $\mathrm{pK}_{\mathrm{a} 2}$ shifts induced by the presence of micelles strongly depend on the protolytic equilibrium involved, on the charge of the micelles and on the dye components absorbed.

$\mathbf{L}$

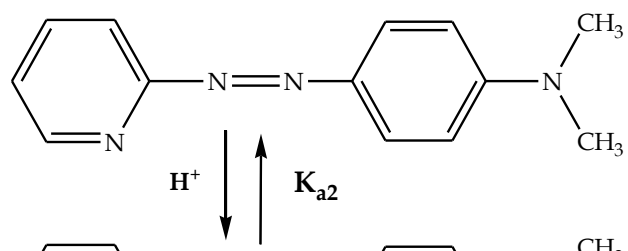

$\mathrm{HL}^{+}$
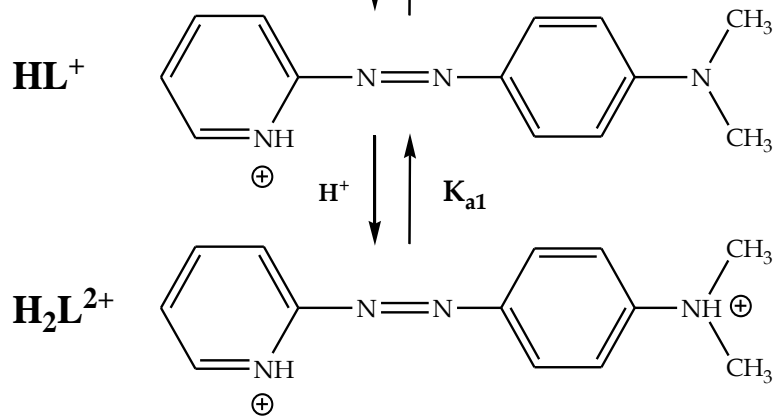

Figure 1 Pyridine-2-azo-p-dimethylaniline (PADA) in its neutral (L) and protonated forms $\left(\mathrm{HL}^{+}\right.$and $\left.\mathrm{H}_{2} \mathrm{~L}^{2+}\right)$.

\section{Materials and Methods}

\subsection{Materials}

The ligand pyridine-2-azo-p-dimethylaniline (PADA) and the surfactants sodium dodecylsulphate were purchased from Sigma-Aldrich. Dodecyltrimethylammonium chloride (DTAC), hydrochloric acid and sodium chloride were from Fluka. Triton X-100 was from Merck. All reactants were analytical grade and were used without further purification. Ultrafiltration membranes made of regenerated cellulose (YM 3, Millipore) of $4.5 \mathrm{~cm}$ diameter, with a molecular weight cut-off of 3000 
Dalton, were used in the ultrafiltration experiments. The membranes were treated and stored as recommended by Millipore. Water from a Millipore MILLI-Q water purification system was used as a reaction medium.

\subsection{Methods}

The $\mathrm{pH}$ measurements were made using a Metrohm 713 instrument. The critical micellar concentration $(\mathrm{cmc})$ of SDS in water was known from electrical conductivity and light scattering measurements $\left(7.9 \times 10^{-3} \mathrm{M},[9,16,21]\right)$. The cmc of our DTAC sample had already been checked by electrical conductivity and surface tension measurements and was found to be $(1.0 \pm 0.1) \times 10^{-2} \mathrm{M}$ [15], somewhat less than the literature value $\left(2 \times 10^{-2} \mathrm{M},[22]\right)$. The TritonX-100 $\mathrm{cmc}\left(2.2 \times 10^{-4} \mathrm{M}\right)$ has been taken from the literature [23].

The amount of PADA adsorbed on the micelle surface was determined by ultrafiltration experiments: $20 \mathrm{ml}$ of an aqueous solution containing the dye and the surfactant at a concentration higher than the cmc were introduced in a $50 \mathrm{~cm}^{3}$ cell and stirred under an applied nitrogen pressure of 1 bar. The cell was equipped with an ultrafiltration membrane whose effective area was $13.4 \mathrm{~cm}^{2}$. Acid dissociation equilibria were investigated by means of a Perkin-Elmer Lambda 35 spectrophotometer. Spectrophotometric titrations were carried out by adding increasing volumes of $\mathrm{HCl}$ to the cell containing the PADA solution. The additions were made by a Hamilton microsyringe connected to a Mitutoyo micrometric screw; such system enables additions as small as $0.166 \mu \mathrm{L}$. The spectrophotometer cells were thermostatted to $\pm 0.1{ }^{\circ} \mathrm{C}$. The titration data were analysed by a non-linear least-square fitting procedure performed by the Jandel statistical package which makes use of the Marquardt algorithm [24].

\section{Results}

\subsection{Ultrafiltration experiments}

The amount of PADA adsorbed was evaluated by spectrophotometry as the difference between the initial amount and that remaining in the permeate after filtration. The dye is strongly adsorbed on 
the surface of all the employed surfactants. In fact, it was found that the percent of adsorbed dye (at $\mathrm{pH}=3.5)$ was $99 \%$ in SDS, $95 \%$ in Triton $\mathrm{X}-100$ and $92 \%$ in DTAC.

\subsection{Spectrophotometric titrations}

The spectral behaviour of PADA depends on $\mathrm{pH}$ and nature of surfactant as shown in Figure 2. Therefore, the (apparent) extinction coefficients, used in the analysis of the titration data, were measured before each titration.

The acid dissociation constants of PADA (i.e. of $\mathrm{HL}^{+}$and $\mathrm{H}_{2} \mathrm{~L}^{2+}$, see Figure 1) were determined by spectrophotometric titrations at $25^{\circ} \mathrm{C}$. Calibrated amounts of $\mathrm{HCl}$ solution were added to the cuvette containing a known amount of PADA initially at $\mathrm{pH} 7.0$.
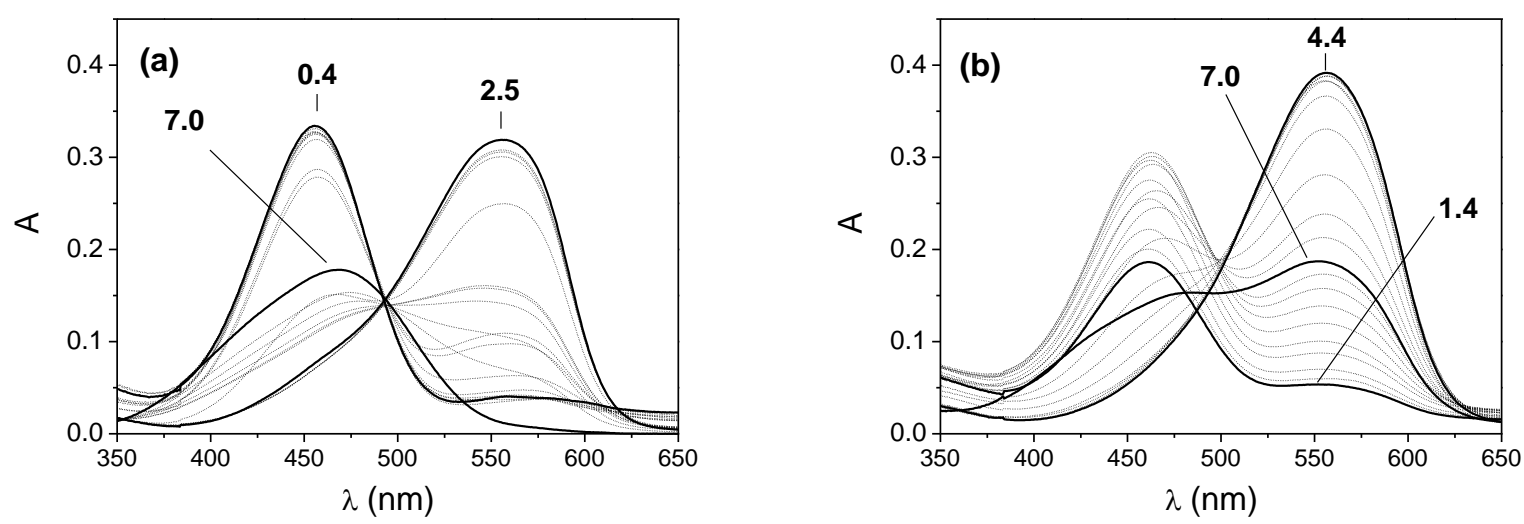

Figure 2 UV-vis spectra of PADA $\left(1 \times 10^{-5} \mathrm{M}\right)$ recorded in water (a) and in SDS $0.02 \mathrm{M}$ micellar solution (b) at $25^{\circ} \mathrm{C}$ and different $\mathrm{pH}$ values (the most significant are shown and labelled on the graph).

The absorbance values at $560 \mathrm{~nm}$ were analysed according to equation (4).

$$
\frac{\Delta A}{C_{L}}=\frac{\Delta \varepsilon_{1} \cdot K_{a 1} \cdot\left[H^{+}\right]+\Delta \varepsilon_{2}\left[H^{+}\right]^{2}}{\left[H^{+}\right]^{2}+K_{a 1} \cdot\left[H^{+}\right]+K_{a 1} \cdot K_{a 2}}
$$


where $\Delta \mathrm{A}=\mathrm{A}-\varepsilon_{\mathrm{L}} \mathrm{C}_{\mathrm{L}}, \mathrm{C}_{\mathrm{L}}$ is the total ligand concentration, $\Delta \varepsilon_{1}=\varepsilon_{\mathrm{HL}}-\varepsilon_{\mathrm{L}}, \Delta \varepsilon_{2}=\varepsilon_{\mathrm{H} 2 \mathrm{~L}}-\varepsilon_{\mathrm{L}}, \varepsilon_{\mathrm{i}}$ the extinction coefficient of the $i$-th species, and $\mathrm{K}_{\mathrm{a} 1}$ and $\mathrm{K}_{\mathrm{a} 2}$ are dissociation constants of $\mathrm{H}_{2} \mathrm{~L}^{2+}$ and $\mathrm{HL}^{+}$respectively (see Figure 1). The hydrogen ion concentration introduced in equation (1) corresponds to the concentration of the added $\mathrm{HCl}$ which is in large excess over the concentration of PADA. Figure 3 shows the experimental data points of typical titration and the curve calculated according to equation (4); the agreement with experiment is very good. Figure 4 shows the dependence of $\mathrm{pK}_{\mathrm{a} 1}$ and $\mathrm{pK}_{\mathrm{a} 2}$ values of PADA on surfactant concentration, in SDS, in DTAC and in Triton $\mathrm{X}-100$. Titrations have been done also in the presence of added salt $(\mathrm{NaCl})$ so that the overall ionic strength was kept constant to $0.2 \mathrm{M}$ (open triangles in Figure 4).

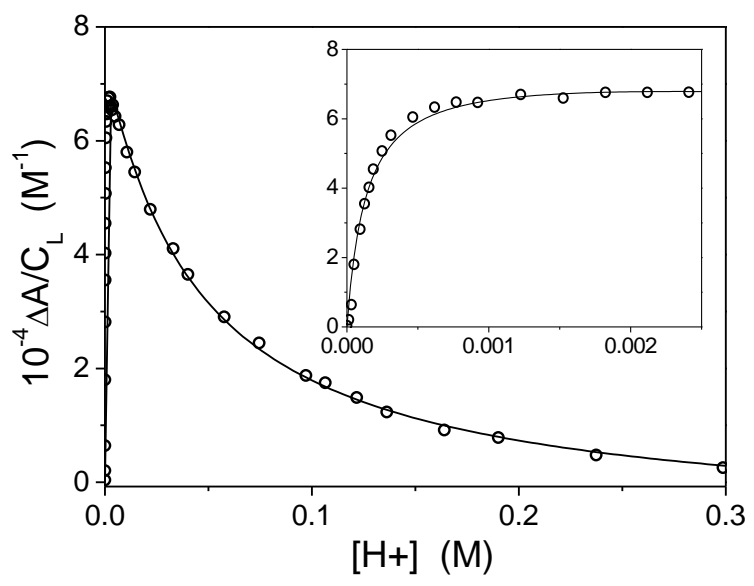

Figure 3 Biphasic binding isotherm for the titration of PADA $\left(1 \times 10^{-5} \mathrm{M}\right)$ with $\mathrm{HCl}$ in DTAC $0.02 \mathrm{M}$ micellar solution at $25^{\circ} \mathrm{C}, \lambda=560 \mathrm{~nm}$; the continuous line represents the calculated trend according to equation (4), the inset is the enlargement of the first part of the plot. 

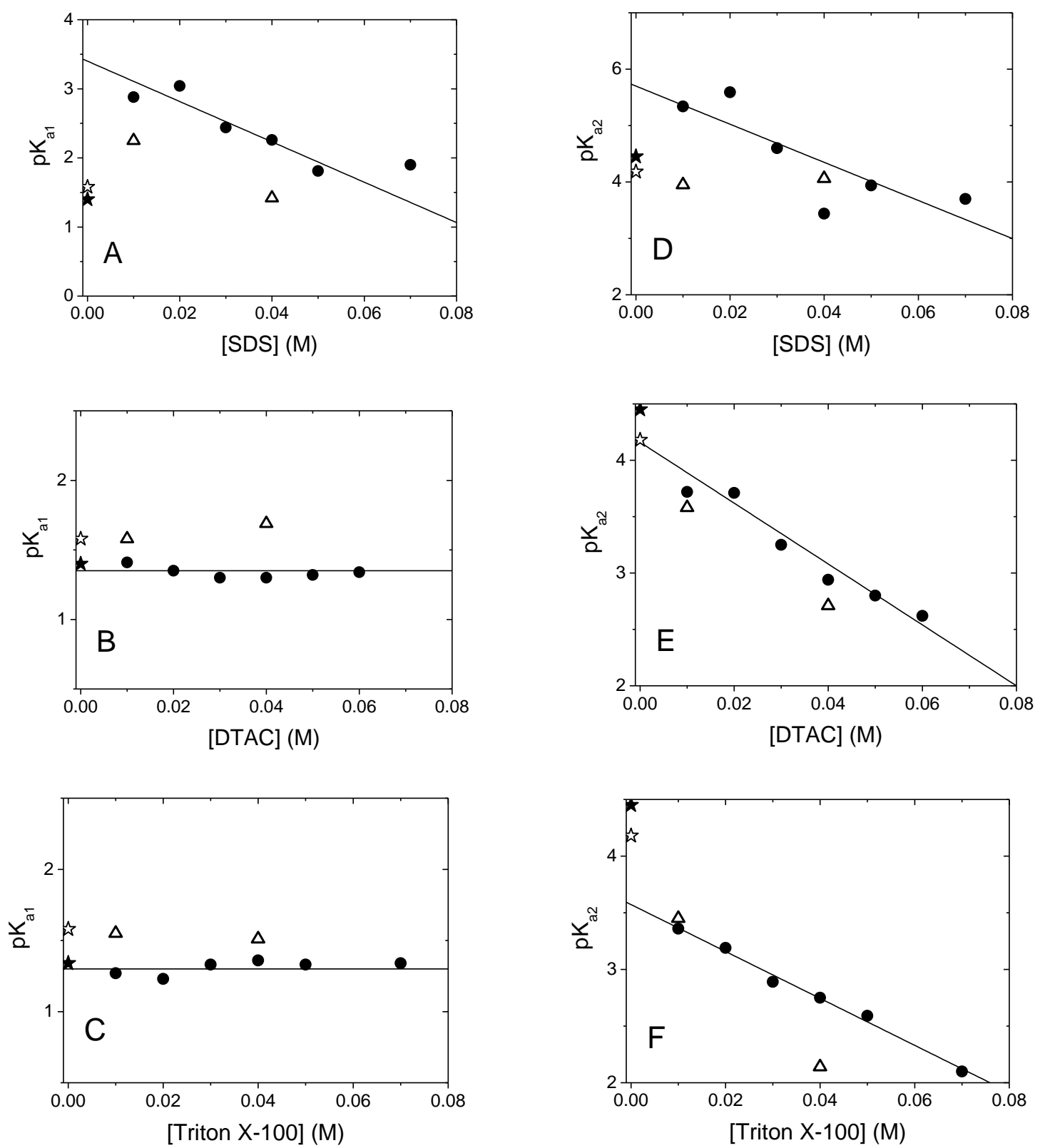

Figure 4 Plots of $\mathrm{pK}_{\mathrm{a} 1}$ of PADA at different surfactant concentrations (A) SDS, (B) DTAC, (C) Triton X-100 and plots of $\mathrm{pK}_{\mathrm{a} 2}$ of PADA at different surfactant concentrations (D) SDS, (E) DTAC,

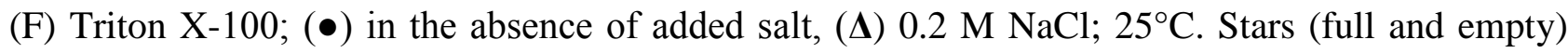
indicate the values in water (without salt and in $0.2 \mathrm{M} \mathrm{NaCl}$ respectively).

The data in the presence of $\mathrm{NaCl} 0.2 \mathrm{M}$ are significantly different to those obtained in the absence of added salt, both as concerns the numerical values and as regards their dependence on the surfactant content that, in $0.2 \mathrm{M} \mathrm{NaCl}$, is strongly reduced in the case of SDS. This result can be 
obtained also on the basis of visual observations. Figure 5A shows PADA/SDS solutions where the acidity level is kept constant $(\mathrm{pH}=5.5)$ and the $\mathrm{NaCl}$ concentration is increased. The colour of PADA changes from pink $\left(\mathrm{H}_{2} \mathrm{~L}^{2+}\right)$ to orange $\left(\mathrm{HL}^{+}\right)$on increasing the salt content. Figure 5B demonstrates this effect is due to $\left[\mathrm{Na}^{+}\right]$and not to chloride ions, as the increase of $\left[\mathrm{Cl}^{-}\right]$does not produce any colour change, provided that the sodium content is kept constant.
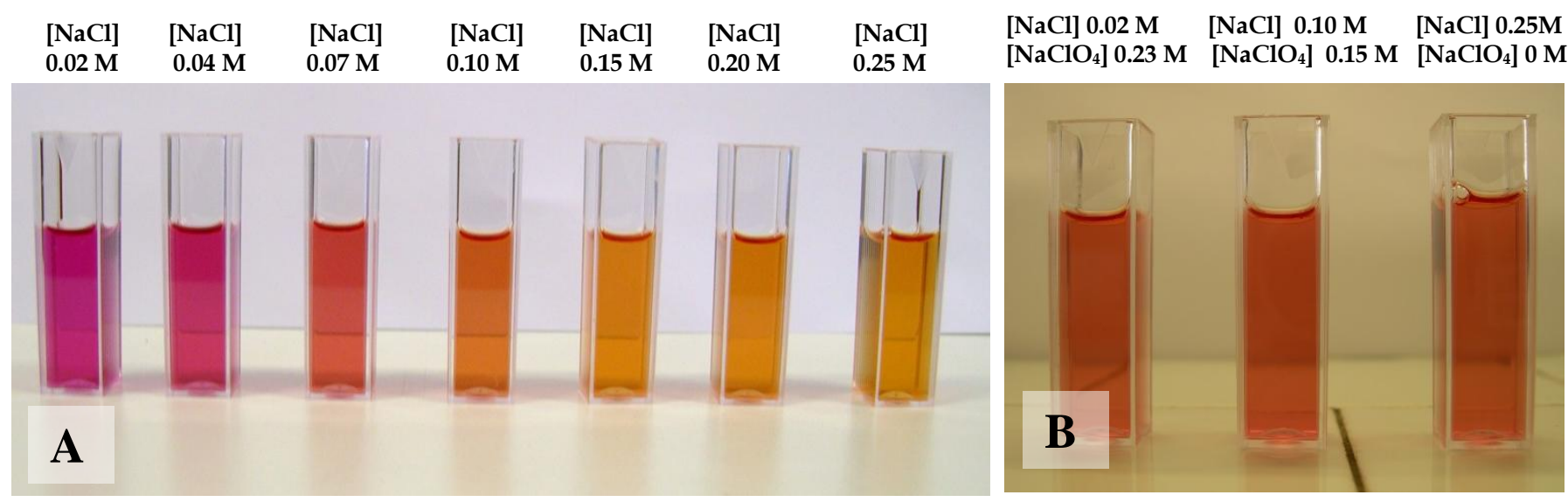

Figure 5. Colour of PADA solutions (A) at constant $\mathrm{pH}$ and different added $\mathrm{NaCl}(\mathrm{B})$ at constant $\mathrm{pH}$ and $\left[\mathrm{Na}^{+}\right]$and different $\mathrm{Cl}^{-}$content. $[\mathrm{PADA}]=4 \times 10^{-5} \mathrm{M},[\mathrm{SDS}]=0.02 \mathrm{M}, \mathrm{pH}=5.5, \mathrm{~T}=25^{\circ} \mathrm{C}$.

\section{Discussion}

It has been assumed in this work that that the addition of the dye to solutions containing the surfactant does not alter the surface properties of the micelles, owing to the very low values of the employed [dye]/[micelle] ratio. The data reported in Figure 4 show that the surfactants here investigated affect the acid dissociation constants of PADA in different ways. Actually, the $\mathrm{pK}_{\mathrm{a} 2}$ values display a decrease for all the studied systems as the surfactant concentration is raised (Figure 4D,E,F). Similar behavior is displayed by $\mathrm{pK}_{\mathrm{a} 1}$ in the presence of SDS (Figure 4A). By contrast, in the presence of DTAC and Triton $\mathrm{X}-100$ the $\mathrm{pK}_{\mathrm{a} 1}$ values are independent on the surfactant concentration and similar to the value in water (Figure 4C,D). We find convenient to discuss the obtained results in terms of the $\mathrm{pK}_{\mathrm{a}}$ shifts, as shown in Table 1 which, in principle, allow 
separating the "intrinsic" shift $\Delta \mathrm{pKai}{ }^{0}$ from the surface potential effect. The values of $\mathrm{pK}_{\mathrm{a} 1}$ and $\mathrm{pK}_{\mathrm{a} 2}$ reported in Table 1 have been derived by extrapolating the data of Figure 4 to [surfactant] $=0 \mathrm{M}$ (straight line in the figures).

Table 1. Values of $\mathrm{pK}_{\mathrm{a} 1}$ and $\mathrm{pK}_{\mathrm{a} 2}$ of PADA in water, SDS, Triton X-100 and DTAC extrapolated at zero micelle concentration and of the relevant shifts with respect to water $\left(\Delta \mathrm{pK}_{\mathrm{a}}{ }^{\mathrm{w}}=\mathrm{pK}_{\mathrm{a}}-\mathrm{pK}_{\mathrm{a}}{ }^{\mathrm{w}}\right)$ and with respect to uncharged Triton $\mathrm{X}-100$ taken as a reference $\left(\Delta \mathrm{pK}_{\mathrm{a}}{ }^{0}=\mathrm{pK}_{\mathrm{a}}-\mathrm{pK}_{\mathrm{a}}{ }^{0}\right) \cdot \mathrm{pKa}_{1}{ }^{\mathrm{w}}=1.4$, $\mathrm{pK}_{\mathrm{a} 2}{ }^{\mathrm{w}}=4.5, \mathrm{~T}=25^{\circ} \mathrm{C}$.

\begin{tabular}{cccccccc}
\hline & SDS & DTAC & Triton X-100 & & SDS & DTAC & Triton X-100 \\
\hline $\mathrm{pK}_{\mathrm{a} 1}$ & 3.4 & 1.35 & 1.3 & $\mathrm{pK}_{\mathrm{a} 2}$ & 5.7 & 4.2 & 3.6 \\
$\Delta \mathrm{pK}_{\mathrm{a} 1}{ }^{\mathrm{w}}$ & 2.0 & -0.05 & -0.1 & $\Delta \mathrm{pK}_{\mathrm{a} 2}{ }^{\mathrm{w}}$ & 1.2 & -0.3 & -0.9 \\
$\Delta \mathrm{pK}_{\mathrm{a} 1}{ }^{0}$ & 2.1 & 0.05 & - & $\Delta \mathrm{pK}_{\mathrm{a} 2}{ }^{0}$ & 2.1 & 0.6 & - \\
\hline
\end{tabular}

\subsection{The PADA/Triton $X-100$ system}

The second dissociation of PADA $\left(\mathrm{HL}^{+}=\mathrm{L}+\mathrm{H}^{+}\right)$in the presence of Triton $\mathrm{X}-100$ displays a value of $\Delta \mathrm{pK}_{\mathrm{a} 2}{ }^{\mathrm{w}}$ of -0.9 . Since in the neutral micelle the potential effect can be disregarded, this shift should coincide with $\Delta \mathrm{pK}_{\mathrm{a}}{ }^{0}$. A similar shift $\left(\Delta \mathrm{pK}_{\mathrm{a}}{ }^{\mathrm{w}}=-1.1\right)$ was observed by Fromherz and Fernandez for the nitrogen acid Aminocoumarin (in the form $\mathrm{HL}^{+}$) in the presence Triton $\mathrm{X}-100$. By comparison with $\mathrm{pK}_{\mathrm{a}}$ measurements in water-dioxane mixtures the above authors concluded that the negative value of $\Delta \mathrm{pK}_{\mathrm{a}}{ }^{\mathrm{w}}$ should be ascribed to a decrease of the dielectric constant at the watermicelle interface, where the reaction site is located. Support to the above conclusion is provided by a study which shows that the $\mathrm{pK}_{\mathrm{a}}$ of protonated amines decrease with decreasing the dielectric constant of the medium [25]. The sign of $\Delta \mathrm{pK}_{\mathrm{a} 2}{ }^{0}$ of PADA depends on the charges of the species participating in the reaction involved. Actually, $\Delta \mathrm{pK}_{\mathrm{a}}{ }^{0}$ is proportional to the free energy required to transfer the acid $\left(\mathrm{HL}^{+}\right)$and the corresponding base (L) from water to the hydrophobic core of the micelle (equation (5)) 
$\Delta \mathrm{pK}_{\mathrm{a}}^{0}=\left[\left(\mu_{\mathrm{L}}^{\mathrm{om}}-\mu_{\mathrm{L}}^{\mathrm{ow}}\right)-\left(\mu_{\mathrm{HL}}^{\mathrm{om}}-\mu_{\mathrm{HL}}^{\mathrm{ow}}\right)\right] / 2.3 \mathrm{RT}$

where $\mu_{\mathrm{L}}^{\mathrm{om}}, \mu_{\mathrm{L}}^{\mathrm{ow}}, \mu_{\mathrm{HL}}^{\mathrm{om}}, \mu_{\mathrm{HL}}^{\mathrm{ow}}$ are respectively the chemical potentials of $\mathrm{L}$ and $\mathrm{HL}^{+}$in the micelle(m) and in water (w). Since a decreased dielectric constant favors the transfer of charged species, in the case of the PADA it results that $\left(\mu_{\mathrm{HL}}^{\circ \mathrm{m}}-\mu_{\mathrm{HL}}^{\circ \mathrm{w}}\right)>\left(\mu_{\mathrm{L}}^{\circ \mathrm{m}}-\mu_{\mathrm{L}}^{\circ \mathrm{w}}\right)$, thus, according to equation (5), the value of $\Delta \mathrm{pK}_{\mathrm{a} 2}{ }^{0}$ is negative. Equation (5) can also explain the smaller shift of $\mathrm{pK}_{\mathrm{a} 1}$ shown in Table 1 . Here, the acid $\left(\mathrm{H}_{2} \mathrm{~L}^{2+}\right)$ and the base $\left(\mathrm{HL}^{+}\right)$are both charged, so the energetic requirements for the transfer can be similar. As a consequence, the resulting $\Delta \mathrm{pK}_{\mathrm{a} 1}{ }^{0}$ value is small.

\subsection{The PADA/SDS system}

It should be noted that in systems involving neutral micelles only the dielectric polarization is present, whereas in systems with charged micelles an additional contribution due to the ionic polarization may have be present. In such a case equation (5) is no more applicable. The results concerning the dissociations of PADA in SDS are conveniently interpreted according to equation (3) which states that the $\mathrm{pK}_{\mathrm{a}}$ shift directly yields the surface potential of the micelle. Actually using the values of $\Delta \mathrm{pK}_{\mathrm{a} 2}{ }^{0}$ reported in Table 1 one obtains $\psi=-126 \mathrm{mV}$ for the second dissociation and from the value of $\Delta \mathrm{pK}_{\mathrm{a} 1}{ }^{0}$ one obtains $\psi=-126 \mathrm{mV}$ for the first dissociation as well. This value is in excellent agreement with the literature data obtained using other indicators as probes of electrical potential in SDS and lies between the inner potential $(\Psi)$ and the zeta potential $(\zeta)$ of SDS micelles [12]. The intermediate value of $\psi$ suggests that both the deprotonation sites of PADA are located neither at the inner nor at the outer surface of the double layer. They presumably stay out of the core but at a distance from it less than the shear layer.

\subsection{The PADA/DTAC system}

Concerning the results obtained in the presence of the positively charged surfactant DTAC, we note that the value of $\mathrm{pK}_{\mathrm{a} 1}$ is similar to that of the PADA/Triton $\mathrm{X}-100\left(\mathrm{pK}_{\mathrm{a} 1}{ }^{0}\right)$. As a consequence, $\Delta \mathrm{pK}_{\mathrm{a} 1}{ }^{0}$ is very small (Table 1), meaning that, according to equation (3), the potential effect is 
strongly reduced compared to that of the PADA/SDS system; actually, the resulting value of $\psi$ is negligible. Looking now at the second dissociation, the value of $\Delta \mathrm{pK}_{\mathrm{a} 2}{ }^{0}(0.6)$ yields $\psi=-36 \mathrm{mV}$, a negative, and therefore meaningless, value. In order to rationalize these findings one can make the hypothesis that, owing to the positive charges present on PADA, the deprotonation sites stay away from the positive surface of DTAC, protruding towards the bulk water. Such an hypothesis is strengthened by the observation that both the $\mathrm{pK}_{\mathrm{ai}}$ values of PADA in DTAC are very similar to the respective aqueous $\mathrm{pK}_{\mathrm{a}}{ }^{\mathrm{w}}$ values.

\section{$4.4 p K_{a}$ dependence on the micelle concentration}

Figure 4D,E,F show that the $\mathrm{pKa}_{2}$ values decrease as the surfactant concentration is raised. The decreasing trend can be explained on a kinetic ground. Consider the two proton transfer reactions occurring on the surface of the micelles: $\mathrm{H}_{2} \mathrm{~L}^{2+} \leftrightarrows \mathrm{HL}^{+}+\mathrm{H}^{+}$and $\mathrm{HL}^{+} \leftrightarrows \mathrm{L}+\mathrm{H}^{+}$. Both are characterised by an association rate constant $\mathrm{k}_{\mathrm{ass}}\left(\mathrm{M} \mathrm{s}^{-1}\right)$ and by a dissociation rate constant $\mathrm{k}_{\mathrm{diss}}$ $\left(\mathrm{s}^{-1}\right)$. As the micelle concentration increases the reaction partners distribute over a larger surface area. Such a dilution effect results in a decrease of the specific rate $\mathrm{k}_{\text {ass }}$ while $\mathrm{k}_{\text {diss }}$ remains unchanged. The conclusion is that $\mathrm{pK}_{\mathrm{a} 2}$ experiences a decrease. Such a behavior has been observed several times in complex formation reactions in micellar media $[15,20,26,27]$. Also, it should be noted that the $\zeta$ potential, and therefore $\psi$, shows a reduction as the micelle concentration increases, which reflects on a change of $\mathrm{pK}_{\mathrm{a}}[8]$. The decreasing trend is displayed by $\mathrm{pK}_{\mathrm{a} 1}$ in the case of SDS, but not for DTAC. The kinetic explanation given above could confirm the hypothesis that in the latter system the protonation sites protrude towards the bulk water. Under these circumstances, the reaction sites of the adsorbed dye become similar to the reaction site in the bulk, i.e. $\mathrm{pK}_{\mathrm{a} 1}=\mathrm{pK}_{\mathrm{a} 1}{ }^{\mathrm{w}}$ so that the variation of micelles concentration does not affect the value of $\mathrm{pK}_{\mathrm{a} 1}$. It should also be noted that, if the above hypothesis is valid, the location of the sites falls in a region where the surface potential is negligible, i.e. $\mathrm{pK}_{\mathrm{a} 1}=\mathrm{pK}_{\mathrm{a} 1}{ }^{\mathrm{w}}$. 


\section{$4.5 p K_{a}$ dependence on the $\mathrm{NaCl}$ concentration}

Figure 4 shows that salt induces significant changes in the investigated systems. Moreover, the experiment of Figure 5 shows that, in the case of the negatively charged SDS micelle, it is the positive $\mathrm{Na}^{+}$ion that drives the color (i.e. the $\mathrm{pK}_{\mathrm{ai}}$ ) differences. An explanation for this behavior could be found in the competition between the $\mathrm{H}^{+}$and the $\mathrm{Na}^{+}$ions for the SDS surface. As $\left[\mathrm{Na}^{+}\right]$is increased, the protons adsorbed are expelled from the surface. As a consequence, the species $\mathrm{HL}^{+}$, undergoes deprotonation with concomitant change of color.

Let's now analyze the behaviors of the individual systems. As far as the first dissociation is concerned, the data of Figure 4 show that, addition of $0.2 \mathrm{M} \mathrm{NaCl}$ to the PADA/SDS system induces a down-shift of $\mathrm{pK}_{\mathrm{a} 1}$ of about 0.8 units. Such a shift can be explained in terms of reduction of the surface potential by the $\mathrm{Na}^{+}$ions which neutralize the negative charges of the SDS micelles. Actually, it has been found that in $\mathrm{NaCl} 0.2 \mathrm{M} \psi$ of SDS is reduced to $-75 \mathrm{mV}$ [13]. The value obtained from $\Delta \mathrm{pK}_{\mathrm{a} 1}{ }^{0}$ in Table 1 is $\psi=-60 \mathrm{mV}$.

The behavior of the PADA/DTAC system is different. Figure $4 \mathrm{~B}$ shows that, concerning the measurements in the absence of surfactant, $\mathrm{pK}_{\mathrm{a} 1}{ }^{\mathrm{w}}$ experiences a small upward shift of 0.23 units on adding $0.2 \mathrm{M} \mathrm{NaCl}$. The observed effect can be explained on the basis of the classic electrostatic theory. Actually, application of the Davies equation with $\mathrm{B}=0.3[28,29]$ reveals that $\mathrm{pK}_{\mathrm{a} 1}{ }^{\mathrm{w}}$ should increase by 0.25 units. The shift remains the same in spite of the addition of increasing amounts of surfactant. The latter observation again supports the idea that the reaction site of the first deprotonation protrudes towards the aqueous phase. Similar behavior is displayed by the PADA/Triton X-100 system. Concerning the second dissociation, the $\mathrm{pK}_{\mathrm{a} 2}{ }^{\mathrm{w}}$ is less sensitive to the salt effect than $\mathrm{pK}_{\mathrm{a} 1}{ }^{\mathrm{w}}$. The electrostatic theory predicts that the second dissociation process should be independent of the ionic strength. In effect, a small shift of less than 0.1 units can be observed on adding $0.2 \mathrm{M} \mathrm{NaCl}$ which could be ascribed to salting out of the neutral HL species [30]. As concerns the PADA/SDS system, Figure 4D shows that raising the $\mathrm{NaCl}$ level to $0.2 \mathrm{M}$ induces a dramatic change of $\mathrm{pK}_{\mathrm{a} 2}$. This parameter, however, is insensitive to changes of the SDS 
concentration. The large downward $\mathrm{pK}_{\mathrm{a} 2}$ shift is explained by the decrease of $\psi$ caused by the addition of $\mathrm{NaCl}$. The independence of $\mathrm{pK}_{\mathrm{a} 2}$ of the SDS level is rationalized by the fact that, at high salt level employed, the surface potential is made constant. The situation of the PADA/ DTAC and PADA/Triton X-100 systems is different. It has been shown that in DTAC the surface potential plays a much more limited role compared to SDS, and in Triton X-100 does not play any role. Hence, it might be reasonable to advance the hypothesis that negative $\mathrm{pK}_{\mathrm{a} 2}$ shifts exhibited by the two systems could be ascribed to a further decrease of about $8 \%$ of the solvent dielectric constant at the reaction sites induced by addition of $0.2 \mathrm{M} \mathrm{NaCl}$ [31].

Acknowledgement. Financial support of "Obra Social La Caixa" is gratefully acknowledged. 


\section{References}

[1] M. Beneito-Cambra, J.M. Herrero-Martinez, G. Ramis-Ramos, Analytical methods for the characterization and determination of nonionic surfactants in cosmetics and environmental matrices, Anal. Methods 5 (2013) 341-354.

[2] P.D.I. Fletcher, M.P. Krafft, R. Strey, Surfactants, Curr. Opin. Colloid. In. 17 (2012) 187187.

[3] G.J. Hirasaki, C.A. Miller, M. Puerto, Recent Advances in Surfactant EOR, Spe J. 16 (2011) 889-907.

[4] A. Hirsch, J.M. Englert, F. Hauke, Wet Chemical Functionalization of Graphene, Accounts Chem. Res. 46 (2013) 87-96.

[5] S.G. Kapadia, B.N. Yagnik, Current trend and potential for microbial biosurfactants, Asian J. Exp. Biol. Sci. 4 (2013) 1-8.

[6] G. Popovic, M. Cakar, D. Agbaba, Acid-base equilibria and solubility of loratadine and desloratadine in water and micellar media, J. Pharmaceut. Biomed. 49 (2009) 42-47.

[7] A.A. Mungray, S.V. Kulkarni, A.K. Mungray, Removal of heavy metals from wastewater using micellar enhanced ultrafiltration technique: a review, Cent. Eur. J. Chem. 10 (2012) 27-46.

[8] G.S. Hartley, J.W. Roe, Ionic concentrations at interfaces, Trans. Faraday Soc. 35 (1940) 101-109.

[9] A.D. James, B.H. Robinson, Micellar catalysis of metal-complex formation - Kinetics of reaction between $\mathrm{Ni}$ (II) and pyridine-2-azo-p-dimethylaniline (PADA) in presence of sodium dodecylsulfate micelles - model system for study of metal-ion reactivity at charged interfaces, J. Chem. Soc. - Faraday Trans. 74 (1978) 10-21.

[10] R.A. Hobson, F. Grieser, T.W. Healy, Surface-potential measurements in mixed micelle systems, J. Phys. Chem. 98 (1994) 274-278.

[11] L.K.J. Tong, M.C. Glesmann, Mechanism of dye formation in color photography. VI. Effect of a nonionic surfactant on the rate of coupling, J. Am. Chem. Soc. 79 (1957) 4310-4313.

[12] P. Mukerjee, K. Banerjee, Surface $\mathrm{pH}$ of micelles using solubilized indicator dyes, J. Phys. Chem. 68 (1964) 3567-3574.

[13] P. Fromherz, B. Masters, Lipid pH Indicators in Monolayers .3. Interfacial pH at Electrically Charged Lipid Monolayers Investigated by Lipoid pH-Indicator Method, Biochim. Biophys. Acta 356 (1974) 270-275.

[14] I.M. Klotz, W.-C.L. Ming, Stability constants for some metal chelates of pyridine-2-azo-pdimethylaniline, J. Am. Chem. Soc. 75 (1953) 4159-4162.

[15] L. Ghezzi, B.H. Robinson, F. Secco, M.R. Tine, M. Venturini, Binding of Pd(II) to PADA in water/micellar system: complex formation, kinetics in water and DTAC solution, Colloid Surf. A 292 (2007) 139-147.

[16] G. Monteleone, L. Morroni, B. Robinson, M.R. Tine, M. Venturini, F. Secco, Metal ion extraction in surfactant solution: $\mathrm{Ni} 2+(\mathrm{aq})$ and $\mathrm{Cd} 2+(\mathrm{aq})$ with the ligands PADA and PAR in SDS micellar systems, Colloids and Surfaces a-Physicochemical and Engineering Aspects 243 (2004) 23-31.

[17] L. Ghezzi, G. Monteleone, B. Robinson, F. Secco, M.R. Tine, M. Venturini, Metal extraction in water/micelle systems: complex formation, stripping and recovery of $\mathrm{Cd}(\mathrm{II})$, Colloid Surf. A 317 (2008) 717-721.

[18] L. Ghezzi, B.H. Robinson, F. Secco, M.R. Tine, M. Venturini, Removal and recovery of palladium(II) ions from water using micellar-enhanced ultrafiltration with a cationic surfactant, Colloid Surf. A 329 (2008) 12-17.

[19] T. Biver, C. Paoletti, F. Secco, M. Venturini, Extraction, separation and recovery of palladium and platinum by a kinetic method combined with ultrafiltration, Colloid Surf. A 441 (2014) 466-473. 
[20] T. Biver, L. Ghezzi, V. Malvaldi, F. Secco, M.R. Tine, M. Venturini, Kinetics and Equilibria of the Interaction of 8-Hydroxyquinoline with Gallium(III) in Water and Sodium Dodecyl Sulfate Solution, J. Phys. Chem. B 113 (2009) 1598-1606.

[21] A. Chattopadhyay, E. London, Fluorimetric determination of critical micelle concentration avoiding interference from detergent charge, Anal. Biochem. 139 (1984) 408-412.

[22] M. Nowakowska, K. Szczubialka, M. Grebosz, Interactions of temperature-responsive anionic polyelectrolytes with a cationic surfactant, J. Colloid Interface Sci. 265 (2003) 214-219.

[23] C. Cuypers, T. Pancras, T. Grotenhuis, W. Rulkens, The estimation of PAH bioavailability in contaminated sediments using hydroxypropyl-beta-cyclodextrin and Triton X-100 extraction techniques, Chemosphere 46 (2002) 1235-1245.

[24] D. Marquardt, An Algorithm for Least-Squares Estimation of Nonlinear Parameters, J. Soc. Ind. App. Math. 11 (1963) 431-441.

[25] E. Pines, G.R. Fleming, Proton-Transfer in Mixed Water Organic-Solvent Solutions Correlation between Rate, Equilibrium-Constant, and the Proton Free-Energy of Transfer, J. Phys. Chem. 95 (1991) 10448-10457.

[26] T. Biver, A. Boggioni, F. Secco, A. Venturini, Gallium(III)/4 (2-pyridylazo)resorcinol system in water and SDS solution: Kinetics and thermodynamics, Langmuir 24 (2008) 36-42.

[27] H.A. Gazzaz, B.H. Robinson, Kinetics involving divalent metal ions and ligands in surfactant self-assembly systems: Applications to metal-ion extraction, Langmuir 16 (2000) 86858691.

[28] C.W. Davies, The extent of dissociation of salts in water. Part VIII. An equation for the mean ionic activity coefficient of an electrolyte in water, and a revision of the dissociation constants of some sulphates, J. Chem. Soc. (1938) 2093-2098.

[29] G.G. Manov, R.G. Bates, W.J. Hamer, S.F. Acree, Values of the Constants in the Debye Hueckel Equation for Activity Coefficients1, J. Am. Chem. Soc. 65 (1943) 1765-1767.

[30] J.E. Prue, Ionic Equilibria, Pergamon Press, 1966.

[31] P.M. Wang, A. Anderko, Computation of dielectric constants of solvent mixtures and electrolyte solutions, Fluid Phase Equilibr. 186 (2001) 103-122. 